\title{
Peritraumatic distress among emergency medical system employees: A proposed cut-off for the Peritraumatic Distress Inventory
}

\author{
Beata Rybojad ${ }^{1, A-B, D, F} \oplus$, Anna Aftyka ${ }^{2, A, C, E \oplus}$, Joanna Milanowska ${ }^{3, D-E \oplus ~}$ \\ ${ }^{1}$ Department of Emergency Medicine, Medical University, Lublin, Poland \\ ${ }^{2}$ Department of Anaesthesiological and Intensive Care Nursing, Medical University, Lublin, Poland \\ ${ }^{3}$ Department of Applied Psychology, Medical University, Lublin, Poland \\ A - Research concept and design, B - Collection and/or assembly of data, C - Data analysis and interpretation, \\ $D$ - Writing the article, E - Critical revision of the article, F - Final approval of article
} Rybojad B, Aftyka A, Milanowska J. Peritraumatic distress among emergency medical system employees: A proposed cut-off for the
Peritraumatic Distress Inventory. Ann Agric Environ Med. 2019; 26(4): 579-584. doi: 10.26444/aaem/105436

\begin{abstract}
Introduction. Emergency medical system (EMS) workers are exposed to traumatic events that may lead to posttraumatic stress disorder (PTSD).

Objectives. The purpose of this study was to explore and discuss the relationship between peritraumatic distress (PD) and elevated posttraumatic stress symptoms (PTSS) in EMS employees.

Material and methods. A cross-sectional study including 100 EMS employees was conducted. Demographic and occupational data were collected for each subject. The Polish version of the Impact of Event Scale-Revised (IES-R) was used to evaluate PTSS and the Polish version of the Peritraumatic Distress Inventory (PDI) was used to determine the level of PD experienced during and immediately after a traumatic event.

Results. The highest scores indicative of distress were obtained on the negative emotions subscale, and the lowest on the loss of control and arousal (LCA) subscales. A strong positive correlation was found between the severity of PD and PTSS. Among the PDI subscales, the severity of PTSS was most strongly correlated with LCA, and had the weakest correlation with sense of threat. The optimal PDI cut-off score for predicting elevated PTSS was 19.

Conclusions. PD is strongly related to elevated PTSS and serves as a useful tool for screening EMS workers at risk of developing PTSD. Individuals with PDI scores of 19 or higher are good candidates for specialist consultations aimed at detecting and treating elevated PTSS.
\end{abstract}

\section{Key words}

paramedics, Peritraumatic Distress Inventory, peritraumatic distress, post-traumatic stress disorder

\section{INTRODUCTION}

While most people experience stressful events in their lifetime, some groups experience a greater degree of trauma compared to others, including emergency medical system (EMS) employees, victims of natural disasters, war veterans, terrorist attack victims, police officers, fire fighters and motor vehicle accident victims $[1,2,3,4]$. One of the major consequences of experiencing a traumatic event is posttraumatic stress disorder (PTSD). In 1980, PTSD was included by the American Psychiatric Association in the Third Edition of Diagnostic and Statistical Manual of Mental Disorders (DSM-III) [5]. Pathognomonic symptoms of PTSD include intrusion (recurrent memories; criterion $B$ in the DSM-V), avoidance of conversations, activities and people that recall the trauma, combined with emotional numbness (criterion C), and arousal (chronic state of emotional arousal), excessive vigilance, irritability, problems with concentration and sleep (criterion D) [6]. Many self-reported questionnaires and assessments on the severity of post-traumatic stress symptoms are used for diagnosing PTSD $[7,8]$.

Address for correspondence: Joanna Milanowska, Department of Applied Psychology, Medical University of Lublin, Poland

E-mail: joannamilanowska@umlub.pl

Received: 12.11.2018; accepted: 13.02.2019; first published: 08.03.2019
The questionnaires used here have some limitations. For example, while the IES-R examines the severity of three clinical symptoms (intrusion, arousal and avoidance) that are necessary to diagnose PTSD, according to the DSM-5 classification, confirmation of the diagnosis also requires adverse changes in cognitive abilities and mood. To confirm PTSD, these symptoms must persist for at least a month. At the same time, it is necessary to confirm exposure to traumatic events and the occurrence of adverse changes in cognition and mood in relation to traumatic events (experienced immediately or intensifying over time), and significant clinical suffering or impairment in social, occupational and other important domains [6]. Therefore, to make a diagnosis it is necessary to conduct a thorough psychiatric examination. Nonetheless, self-reported questionnaires remain an important tool for screening and scientific research.

In 1994, the diagnostic criteria for PTSD were updated. Traumatic events were included in the so-called criteria A category, with a requirement of a cause-and-effect relationship between A1 (experience or being a witness to a tragic event) and A2 (a reaction in the form of peritraumatic distress [PD], characterised by fear, a sense of helplessness and horror). Although criterion A2 [6] has been removed from the DSM-V, PD remains a strong predictor of posttraumatic stress symptoms (PTSS) [9]. One of the tools 
used for clinical evaluation of PTSD is the Peritraumatic Distress Inventory (PDI) [10]. The PDI has been validated in several languages and its usefulness is recognised in many countries and populations $[9,11,12,13,14]$. In two studies, population-specific optimal PDI cut-offs were determined for predicting PTSD $[2,12]$. Encouraged by these results, we sought to determine the optimal PDI cut-off for a group of EMS employees in Poland. We sought to address the question of whether this screening tool can predict elevated PTSS in paramedics.

\section{OBJECTIVE}

The purpose of this study was to demonstrate a link between PD and elevated PTSS in EMS employees. We hypothesised that a simple 12-item questionnaire could predict PTSS in this occupational group. Based on a search of online medical databases, our study is the first to explore the optimal PDI cut-off for EMS workers.

\section{MATERIALS AND METHODS}

\section{Design and participants}

A cross-sectional study of EMS employees was conducted using baseline data from a randomised representative sample selected from among a total of 20 medical services in central-eastern Poland. Two hundred questionnaires were distributed to EMS employees and 108 were returned along with written informed consent. Eight individuals returned incomplete questionnaires. Rural and urban services were included in the study. The final cohort consisted of 100 EMS workers aged 20 to 61 years (mean, $35.98 \pm 10.24$ years), whose work experience ranged from 6 months to 40 years. Men predominated, representing $72 \%$ of the respondents. The vast majority of respondents, of whom $44 \%$ worked full-time and $32 \%$ worked more than one full-time job, were employed by the public EMS.

\section{Measures}

We used two standardised tools: the PDI and of the Impact of Event Scale-Revised (IES-R).

The PDI was developed to assess PD [10]. For this study, a Polish 3-factor version of the PDI adapted by Rybojad and Aftyka was used [9]. It consists of 12 statements describing PTSD symptoms and evaluates both the sense of threat, and various emotional reactions experienced during and instantly after a major event; the higher the PDI score, the greater the level of distress (Table 1). Three factors were evaluated: loss of control and arousal (LCA, factor 1), negative emotions (NE, factor 2), and feeling of threat (FT, factor 3).

The Cronbach's coefficient alpha for the entire scale $(12$ items) was 0.79 for our study cohort.

The IES-R, developed by Weiss and Marmar (1997) is a 22-item self-report scale that assesses the symptoms of PTSD over the past 7 days. It includes items relevant to intrusion (8 items), avoidance (8 items), and arousal (6 items) [15]. A Polish version of the IES-R, adapted by Juczynski and Bulik (2009), was used in the present study [16]. Symptoms of intrusion include repeatedly reliving memories of the event, accompanied by extreme distress. Arousal is characterised by increased vigilance, anxiety, impatience, and difficulty concentrating. Avoidance encompasses efforts to avoid or escape from thoughts, emotions, or conversations associated with the trauma. Items on both the PDI and IES-R scales were scored on a five-point Likert-type scale ( 0 , not at all; 1 , slightly; 2 , somewhat; 3 , very; and 4, extremely). The outcome measure was PTSS, as evaluated by the IES-R. Generally, the IES-R (and IES) is not used to diagnose PTSD; however, cut-off scores for a preliminary diagnosis of elevated PTSS or PTSD have been cited in the literature [15]. In this study, elevated PTSS was recognized when intrusion, arousal and avoidance, as indexed by the IES $-\mathrm{R}$, exceeded 1.5 points, which can be considered a more conservative approach. Demographic and occupational data were also collected.

Table 1. The Polish version of Peritraumatic Distress Inventory

\begin{tabular}{lc}
\hline Item & Factor \\
\hline 1. I felt helpless. & 2 \\
\hline 2. I felt sadness and grief. & 2 \\
\hline 3. I felt frustrated or angry. & 2 \\
\hline 4. I felt afraid for my own safety. & 3 \\
\hline 5. I felt ashamed of my emotional reactions. & 2 \\
\hline 6. I felt worried about the safety of others. & 3 \\
\hline 7.I had the feeling I was about to lose control of my emotions. & 1 \\
\hline 8. I had difficulty controlling my bowel and bladder. & 1 \\
\hline 9. I was horrified by what I saw. & 1 \\
\hline 10. I had physical reactions like sweating, shaking, and my heart & 1 \\
\hline pounding. & 1 \\
\hline 11. I felt I might pass out. & 1 \\
\hline
\end{tabular}

PD - peritraumatic distress; Factor 1 - loss of control and arousal; Factor 2 - negative emotions; Factor 3 - feeling of threat.

\section{Data analysis}

The data were subjected to statistical analysis. Data reported include percentages, mean values with standard deviation, and first, second and third quartiles. Data normality was assessed by the Shapiro-Wilk test. A Mann-Whitney U test was used to detect significant differences between independent groups. Spearman's correlation coefficient was applied to assess comorbidities of distress and post-traumatic stress symptoms. The relationship between true-positive and false-positive rates was explored by receiver operating characteristic (ROC) curve analysis, in addition to the accuracy, sensitivity, specificity, and positive and negative predictive value of the PDI. A significance level of $p<0.05$ was used. Statistical analyses were performed with IBM SPSS Statistics (ver. 25.0; IBM Corp., Armonk, NY, USA).

\section{Ethics}

The study is a part of a larger project and was approved by the Ethics Committee of the Medical University of Lublin. The work was carried out in accordance with The Code of Ethics of the World Medical Association.

\section{RESULTS}

\section{Sample characteristics}

Participant characteristics are shown in Table 2. 
Table 2. Participant characteristic $(n=100)$

\begin{tabular}{|c|c|c|c|}
\hline & & $\mathrm{n}$ & $\%$ \\
\hline \multirow{2}{*}{ Gender } & Female & 28 & 28.0 \\
\hline & Male & 72 & 72.0 \\
\hline \multirow{3}{*}{ Education status } & Secondary & 36 & 36.0 \\
\hline & Bachelor & 39 & 39.0 \\
\hline & University degree & 25 & 25.0 \\
\hline \multirow{4}{*}{ Provider type } & Physician & 7 & 7.0 \\
\hline & Nurse & 15 & 15.0 \\
\hline & Paramedic & 76 & 76.0 \\
\hline & Dispatcher & 13 & 13.0 \\
\hline \multirow{4}{*}{ Workplace } & MET & 72 & 72.0 \\
\hline & HEMS & 5 & 5.0 \\
\hline & ED & 34 & 34.0 \\
\hline & $\mathrm{EDC}$ & 19 & 19.0 \\
\hline \multirow{4}{*}{$\begin{array}{l}\text { Type of } \\
\text { employment }\end{array}$} & Contract of employment: 1 full-time & 44 & 44.0 \\
\hline & More 1 full-time & 32 & 32.0 \\
\hline & Only contract for a work / order & 4 & 4.0 \\
\hline & Contract solely & 20 & 20.0 \\
\hline \multirow{3}{*}{$\begin{array}{l}\text { Seniority (years of } \\
\text { work experience) }\end{array}$} & $<10$ years & 45 & 45.0 \\
\hline & $10-19$ years & 31 & 31.0 \\
\hline & $\geq 20$ years & 24 & 24.0 \\
\hline
\end{tabular}

MET-Medical Emergency Team, HEMS - Helicopter Emergency Medical Service, ED - Emergency Department, EDC - Emergency Dispatch Centre

The mean PD score on the PDI was $1.14 \pm 0.59$ points, but symptom intensity varied among participants. Scores were highest on the NE subscale (1.62 \pm 0.89$)$, slightly lower on the FT subscale (1.22 \pm 1.09$)$, and lowest on the LCA subscale $(0.79 \pm 0.61)$. The PD distribution showed a near-normal distribution, while the LCA, NE, FT and PTSS were nonnormally distributed (Table 3 ).

Table 3. Descriptive statistics and the normal distribution of analyzed variables $(n=100)$

\begin{tabular}{lccccccccc}
\hline & M & SD & Min. & Q1 & Q2 & Q3 & Max. & $\begin{array}{c}\text { Shapiro- } \\
\text { Wilk }\end{array}$ & $p$ \\
\hline $\begin{array}{l}\text { PD } \\
\text { (total } \\
\text { score) }\end{array}$ & 13.63 & 7.09 & 0.00 & 9.50 & 10.00 & 19.00 & 34.00 & $W=0.982$ & $\mathrm{p}=0.193$ \\
\hline LCA & 0.79 & 0.61 & 0.00 & 0.33 & 0.67 & 1.17 & 2.67 & $W=0.930$ & $\mathrm{p}<0.001$ \\
\hline NE & 1.62 & 0.98 & 0.00 & 1.00 & 1.50 & 2.50 & 3.75 & $W=0.965$ & $\mathrm{p}<0.01$ \\
\hline FT & 1.22 & 1.09 & 0.00 & 0.00 & 1.00 & 2.00 & 4.00 & $W=0.902$ & $\mathrm{p}<0.001$ \\
\hline $\begin{array}{l}\text { PTSS } \\
\text { (total }\end{array}$ & 22.61 & 18.02 & 0.00 & 7.00 & 21.50 & 35.00 & 77.00 & $W=0.940$ & $\mathrm{p}<0.001$ \\
score) & & & & & & & & & \\
\hline
\end{tabular}

PD - Peritraumatic distress; LCA - Loss of Control and Arousal; NE - Negative Emotions; FT Feeling of Threat; PTSS - Posttraumatic Stress Symptoms; M - mean; SD - standard deviation Min. - minimum; Q1 - First quartile; Q2 - Second quartile; Q3 - Third quartile; Max-maximum.
No significant differences were detected in PD, LCA, NE, or FT by gender, level of education, occupation, between respondents working in outgoing teams and in other workplaces, regardless of how they were employed, or level of seniority.

Almost half of the respondents $(n=47)$ reported specific traumatic events that triggered unpleasant symptoms. Common traumatic events included witnessing the death of a child $(n=6)$ or adult $(n=5)$, and aiding victims of sexual violence $(n=4)$ or those with severe injuries $(n=4)$. Respondents who described specific traumatic events were characterised by significantly higher PTSS and NE scores. This group also showed elevated levels of PD and LCA that approached statistical significance (Table 4).

The overall incidence of elevated PTSS was $19 \%$. Respondents who described experiencing a traumatic event had a higher incidence of PTSS compared to the group that did not (27.66\% and $11.32 \%$, respectively).

Given the greater reliability of data obtained from respondents who described the traumatic event, further analyses were limited to this group. There was a strong positive correlation between PD and the severity of PTSS $(\mathrm{r}=0.78, \mathrm{p}<0.05)$. The strongest association was between PTSS severity and LCA $(r=0.63, p<0.05)$, followed by that between PTSS and NE $(\mathrm{r}=0.45, \mathrm{p}<0.05)$, and then PTSS and FT $(\mathrm{r}=0.34, \mathrm{p}<0.05)$ (Table 5).

Table 5. Spearman's correlation matrix: PD, LCA, NE, FT, PTSS in the group of respondents who described the traumatic event $(n=47)$

\begin{tabular}{lccccc}
\hline & PD & LCA & NE & FT & PTSS \\
\hline PD & $x$ & & & & \\
\hline LCA & $0.78^{*}$ & $x$ & & & \\
\hline NE & $0.63^{*}$ & 0.16 & $x$ & & \\
\hline FT & $0.45^{*}$ & 0.37 & -0.07 & $x$ & \\
\hline PTSS & $0.81^{*}$ & $0.63^{*}$ & $0.56^{*}$ & $0.34^{*}$ & $x$
\end{tabular}

PD - peritraumatic distress; LCA - loss of control and arousal; NE - negative emotions; FT-feeling of threat; PTSS - posttraumatic stress symptoms; ${ }^{*} p<0.05$

The ROC curves for elevated PTSS on the PDI in the group of respondents who described experiencing a traumatic event $(\mathrm{n}=47)$ are presented in Figure 1.

The area under the ROC curve (AUC) is 0.93, with the lower limit of the asymptotic $95 \%$ confidence interval being 0.86 and the upper limit 1.00. This indicates high goodness of fit and test accuracy. The optimal cut-off for PDI is $\geq 19$ points, based on which 30 respondents were categorised as not at risk of elevated PTSS; of these respondents, 29 had true-negative results and 1 had false-negative results. The negative predictive value was 0.97 . Of the 17 subjects that were considered at risk of elevated PTSS, 12 had true-positive and

Table 4. Differences in PD, LCA, NE, FT and PTSS levels between respondents who described or did not describe a traumatic event ( $\mathrm{n}=100$ )

\begin{tabular}{|c|c|c|c|c|c|c|c|c|c|c|c|c|}
\hline & \multicolumn{5}{|c|}{ Description of the traumatic event $(n=47)$} & \multicolumn{5}{|c|}{ No description of the traumatic event $(n=53)$} & \multirow{2}{*}{$\begin{array}{c}\text { U Mann-Whitney } \\
\text { Test }\end{array}$} & \multirow{2}{*}{$\mathrm{p}$} \\
\hline & M & SD & Q1 & Q2 & Q3 & M & SD & Q1 & Q2 & Q3 & & \\
\hline PD & 15.13 & 6.83 & 10.00 & 15.00 & 19.00 & 12.30 & 7.13 & 7.00 & 13.00 & 17.00 & 966.500 & 0.054 \\
\hline LCA & 0.91 & 0.644 & 0.33 & 0.83 & 1.167 & 0.68 & 0.56 & 0.33 & 0.50 & 1.00 & 994.000 & 0.081 \\
\hline $\mathrm{NE}$ & 1.86 & 0.99 & 1.00 & 1.75 & 2.75 & 1.40 & 0.93 & 0.75 & 1.25 & 2.00 & 957.500 & 0.046 \\
\hline FT & 1.12 & 1.01 & 0.00 & 1.00 & 1.50 & 1.30 & 1.15 & 0.00 & 1.00 & 2.00 & 1140.000 & 0.461 \\
\hline
\end{tabular}

PD - peritraumatic distress; LCA - loss of control and arousal; NE - negative emotions; FT - feeling of threat; PTSS - posttraumatic stress symptoms 


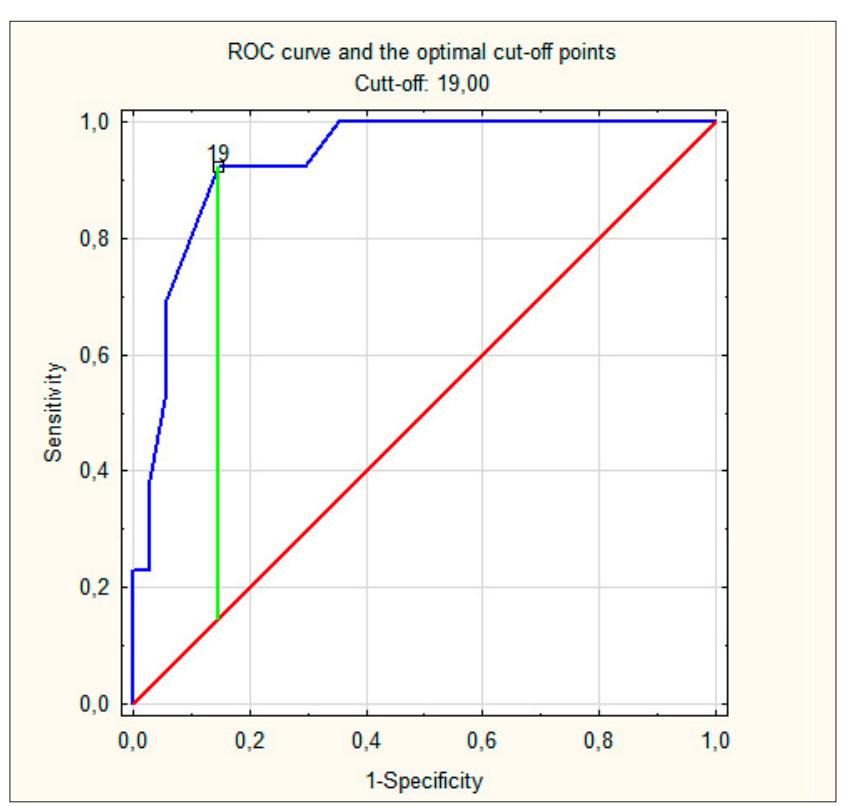

Figure 1. The receiver operating characteristic curves for elevated posttraumatic stress symptoms (PTSS) on the Peritraumatic Distress Inventory (PDI) in the group of respondents who described the traumatic event $(n=47)$.

5 had false-positive results. The positive predictive value was 0.72. These results indicate that PDI is an effective tool for identifying people without elevated PTSS. The test sensitivity and specificity were 0.92 and 0.85 , respectively (Table 6).

Table 6. PD in elevated PTSS prediction; cut-off $\geq 19$;Point estimates and $95 \% \mathrm{Cl}$ in the group of respondents who described the traumatic event $(n=47)$

\begin{tabular}{lcc}
\hline & \multicolumn{2}{c}{ Elevated PTSS } \\
\cline { 2 - 3 } & Positive $(\mathrm{n}, \%)$ & Negative $(\mathrm{n}, \%)$ \\
\hline Positive: PDI $\geq 19(\mathrm{n}, \%)$ & $12(70.59)$ & $5(29.41)$ \\
\hline Negative: PDI $<19(\mathrm{n}, \%)$ & $1(3.33)$ & $0.92(0.64,1.00)$ \\
\hline Sensitivity & \multicolumn{2}{c}{$0.85(0.69,0.95)$} \\
\hline Specificity & $0.71(0.44,0.90)$ \\
\hline Positive predictive value & $0.97(0.83,1.00)$ \\
\hline Negative predictive value & \multicolumn{2}{c}{0} \\
\hline
\end{tabular}

PD - peritraumatic distress; PTSS - posttraumatic stress symptoms

\section{DISCUSSION}

Despite the increased awareness of distress and PTSD among the general population and EMS employees in Poland, aimed at PTSD prevention and therapy are insufficient $[17,18]$. The worldwide PTSD rate ranges between $3 \%$ and $5 \%$ in the general working population [10]. In Poland, the rate was estimated at $10-16 \%$ [19]. PTSD can develop in people who have experienced a particularly traumatic event involving mortal danger or a threat to physical integrity (e.g. death of a loved one, rape, car accident, restriction of freedom, sudden illness or disability) [9]. In a previous US study including 5,877 randomly selected participants, a higher percentage of PTSD occurred in a group of women who had been married previously but were now single due to divorce, separation or death of their spouse. In contrast, married men had a higher PTSD score than those who were never married. PTSD was significantly more common in women than men in the study (10\% of women and $5 \%$ of men), and in the entire study population, a positive relationship was found between PTSD and reportage of at least one affective disorder by the respondent [20]. In the current study, a strong positive correlation was found between distress and PTSD symptoms, which is in line with a meta-analysis of 19 studies [21]. The authors of that analysis indicated that the strength of the correlation decreased with time between the traumatic experience and the assessment of distress level, which may relate to the incidence of recurring memories.

The worldwide prevalence of PTSD among EMS workers ranges from several to several tens of percent $[17,22,23$, 24]. Streud et al. conducted a systematic review of studies of EMS paramedics and reported that the prevalence of PTSS exceeded $20 \%$ in five studies, and similarly high prevalence rates were reported for anxiety and general psychopathology in four of five studies [24]. However, some studies indicated a significantly lower PTSD rate among EMS employees. For example, $6 \%$ of rescue workers helping victims of a bomb attack in London displayed probable PTSD 2 months after the attack, compared to $4 \%$ in the control group. It should be emphasised that most of the surveyed rescuers were aware of the available support and how to access to it, where such support serves as a PTSD preventative measure [22]. In Poland, the frequency of elevated PTSS symptoms in EMS employees appears to be relatively high; it was $19 \%$ in the present study, which is similar to other reports $[25,26]$. According to Wojciszke (2005), a high percentage of PTSD can be explained by a cultural propensity, namely the Polish "culture of complaining" [27].

Our study did not show sex differences in the experience of PD, LCA, NE or FT. This finding is in opposition to other published results, which indicate that among victims of violence, women experienced greater PDI than men [28]. The discrepancy may be explained by the fact that the other studies included different types of populations. A strength of the present analysis lay in its focus on EMS employees. This is the first study to examine the relationship between PD and elevated PTSS in this population, and the first to show that PD, as well as LCA, NE and FT, are associated with elevated PTSS in this group. It is noteworthy that LCA, which was the domain least affected by critical events among our EMS population, typically has the strongest link with PTSS. In EMS employees, mastering one's own reactions and undertaking rational actions in situations of threat to life and health of one's own or other people is crucial for the effectiveness of undertaken actions. In this context, it is not surprising that the loss of control and arousal has, among the symptoms of peri-traumatic distress, the smallest severity and is most strongly associated with PTSS.

The function of diagnostic cut-off values for PTSD is to differentiate individuals with symptoms of distress from those without symptoms. On the basis of the ROC curves, we determined that the optimal cut-off score for the Polish version of the PDI, for diagnosis of elevated PTSS, was $\geq 19$, similar to previous studies. However, those studies considered included different populations. Nishi et al (2009) demonstrated that the optimum PDI cut-off for motor vehicle accident victims was $\geq 23$ (i.e. higher than that for our cohort). Sensitivity and specificity were lower in that study compared to the current study ( $77 \%$ and $82 \%$ vs, $85 \%$ and $87 \%$, respectively), while negative predictive value was 
higher (93\% vs. $87.5 \%$ ), but positive predictive value was lower (53\% vs. $80 \%$ ) [12]. Another study on motor vehicle accident victims used cut-off PDI values for PTSD, as well as the full spectrum of trauma-related disorders. They recommended immediate care and follow-up for victims with a PDI total score $>28$ [2]. The authors claimed that the predictive value of the PDI was greatest when used early after a traumatic event. Our participants were asked to focus on stressful circumstances that had taken place at least 7 days before completing the questionnaire. A recent study on a group of traumatically injured patients suggested that the PDI is a good measure of PD, with a cut-off score of 23 being optimal for predicting elevated PTSS at 30 days post-injury [29].

There were some limitations to this study that will be addressed in future. Firstly, we did not enquire about alcohol and drug abuse or mental health problems. In our opinion, the respondents' answers may have misrepresented the truth even though the data were anonymous. Another limitation was that paramedics are exposed to traumatic events in their daily work. In the IES-R manual, there is space to describe a traumatic event in relation to the symptoms experienced, but the instructions do not specify that the time at which the event took place be noted. Therefore, rescue workers could be describing their reactions to an event that occurred in the month before completing the questionnaire. In similar studies, an additional question posed after completing the IES-R, concerning the time that had passed between a traumatic event and the description thereof, was included. This allows respondents who report symptoms related to an event that occurred during the last month to be excluded. It appears that, in previous studies applying the IES-R to EMS employees, the criterion of symptom persistence for at least 4 weeks following a traumatic event was not employed. Another issue in this study was the lack of data to confirm the representativeness of the questionnaire responses. Despite efforts to ensure anonymity, the percentage of correctly completed questionnaires was average. Furthermore, a completely sociodemographically representative profile of respondents was not obtained due to the requirement for informed consent.

\section{CONCLUSIONS}

1. PDI represents a useful tool for screening EMS workers at risk of elevated PTSS and posttraumatic stress disorder. Polish medical rescue system employees with a score of 19 or more on the PDI should consider professional consultations aimed at detecting and treating elevated PTSS.

2. Additional longitudinal studies, which administer the PDI directly after exposure to a major event, and IES-R data obtained after an appropriate interval, are needed to confirm the associations reported herein.

\section{Disclosure statement}

No potential conflict of interest is reported by the authors.

\section{Relevance to clinical practice}

- The PDI, validated and adapted for use in EMS employees, is a simple and reliable screening tool.

- EMS employees are routinely exposed to traumatic events, making this PD screening test especially useful.

\section{REFERENCES}

1. Bossini L, Ilaria C, Koukouna D. PTSD in victims of terroristic attacks - a comparison with the impact of other traumatic events on patients' lives. Psychiatria Pol. 2016; 31: 907-921.

2. Guardia D, Brunet A, Duhamel A, Ducrocq F, Demarty A, Vaiva. Prediction of trauma-related disorders: A proposed cutoff score for the Peritraumatic Distress Inventory. Primary Care Companion CNS Disorder. 2013; 15(1). pii: PCC.12101406.

3. Kim JE, Dager SR, Jeong HS. Firefighters, posttraumatic stress disorder, and barriers to treatment: Results from a nationwide total population survey. PLoS One. 2018; 13(1): e0190630. doi: 10.1371/ journal.pone.0190630. eCollection 2018.

4. Nishi D, Koido Y, Nakaya N, Sone T, Noguch H, Hamazaki K. et al. Peritraumatic distress, watching television, and posttraumatic stress symptoms among rescue workers after the Great East Japan earthquake. PLoS One. 2012; 7(4): e35248. doi: 10.1371/journal.pone.0035248.

5. American Psychiatric Association. Diagnostic and Statistical Manual of Mental Disorders, third ed. American Psychiatric Association, Washington DC, 1980. http://dsm.psychiatryonline.org/doi/ pdf/10.1176/appi.books.9780521315289.dsm-iii (access: 2018.04.18).

6. American Psychiatric Association. Diagnostic and Statistical Manual of Mental Disorders, fifth ed. American Psychiatric Association, Washington DC, 2013. https://dsm.psychiatryonline.org/doi/ book/10.1176/appi.books.9780890425596 (access: 2018.05.20).

7. Gelaye E, Zheng Y, Medina-Mora, ME, Rondon MB, Sánchez SE, Williams MA. Validity of the posttraumatic stress disorders (PTSD) checklist in pregnant women. BMC Psychiatry. 2017; 17: 179. Epub 2017 May 12. doi: 10.1186/s12888-017-1304-4.

8. Suzuki Y, Yabe H, Horikoshi N, Yasumura S, Kawakami N, Ohtsuru A, et al. Mental Health Group of the Fukushima Health Management Survey. Diagnostic accuracy of Japanese posttraumatic stress measures after a complex disaster: the Fukushima Health Management Survey. Asia Pacific Psychiatry. 2017; Epub 2016 Aug 9. doi: 10.1111/appy.12248.

9. Rybojad B, Aftyka A. Validity, reliability and factor analysis of the Polish version of the Peritraumatic Distress Inventory. Psychiatria Polska Online first. 2017; 84: 1-15, doi: https://doi.org/10.12740/PP/ OnlineFirst/75122. (access: 2018.04.15)

10. Brunet A, Weiss DS, Metzler TJ, Best SR, Neylan TC, Rogers C, et al. The Peritraumatic Distress Inventory: a proposed measure of PTSD criterion A2. Am J Psychiatry. 2001; 158: 1480-1485.

11. Bui EA, Brunet A, Olliac E, Very E, Allenou C, Raynaud JP, et al. Validation of the Peritraumatic Dissociative Experiences Questionnaire and Peritraumatic Distress Inventory in school-aged victims of road traffic accidents. European Psychiatry. 2011; 26: 108- 111. doi: 10.1016/j. eurpsy.2010.09.007.

12. Nishi D, Matsuoka Y, Noguchi H, Sakuma K, Yonemoto N, Yanagita, T, et al. Reliability and validity of the Japanese version of the Peritraumatic Distress Inventory. General Hospital Psychiatry. 2009; 31: 75-79.

13. Kianpoor M, Amouchie R, Raghibi M, Hesam S, Mazidi M, Abasian M. et al. Validity and reliability of Persian versions of peritraumatic distress inventory (pdi) and dissociative experiences scale (des). Acta Medica Mediterranea. 2016; 32: 1493-1501.

14. Jehel L, Brunet A, Paterniti S, Guelfi JD. Validation of the Peritraumatic Distress Inventory's French translation. Can J Psychiatry. 2005; 50: 67-71.

15. Weiss DS, Marmar CR. The Impact of Event Scale-Revised. In: Wilson JP, Keane TM. red. Assessing psychological trauma and PTSD. New York, NY: Guilford Press. 1997; 399-411.

16. Juczynski Z, Oginska-Bulik N. Measurement of post-traumatic stress disorder- Polish version of Impact Event Scale-Revised. Psychiatry. 2009; 6: 15-25.

17. Bennett P, Williams Y, Page N, Hood K, Woollard M. Levels of mental health problems among UK emergency ambulance workers. Emerg Med J. 2004; 21: 235-236.

18. Ogińska-Bulik N. Rola strategii radzenia sobie ze stresem w rozwoju po traumie u ratowników medycznych (The role of doping strategies in posttraumatic growth in medical rescue workers). Occup Med. 2014; 65: 209-217 (in Polish).

19. Lis-Turlejska M. Stres traumatyczny. Występowanie, następstwa, terapia (Traumaticstress. Occurrence, outcome, therapy). Academic Publ. Żak Warsaw. 2002.

20. Kessler RC, Sonnega A, Bromet E. Posttraumatic stress disorders in the national comorbidity survey. Arch Gen Psychiatry. 1995; 52: 1048-1060.

21. Thomas É, Saumier D, Brunet A. Peritraumatic distress and the course of posttraumatic stress disorder symptoms: a meta-analysis. Canadian Journal of Psychiatry. 2012; 57: 122-129. 
22. Misra M, Greenberg N, Hutchinson C, Brain A, Glozier N. Psychological impact upon London Ambulance Service of the 2005 bombings. Occup Med (Lond). 2009; 59: 428-433.

23. Rybojad B, Aftyka A, Baran M, Rzońca P. Risk Factors for Posttraumatic Stress Disorder in Polish Paramedics: A Pilot Study. J Emer Med. 2016; 50: 270-276.

24. Sterud T, Ekeberg O, Hem E. Health status in the ambulance services: a systematic review. BMC Health Services Res. 2006; 6:82. doi: 10.1186/1472-6963-6-82.

25. Kucmin T, Kucmin A, Turska D, Turski A, Nogalski A. Coping styles and dispositional optimism as predictors of post-traumatic stress disorder (PTSD) symptoms intensity in paramedics. Psychiatr Pol. 2018; 30; 52(3): 557-571. doi: 10.12740/PP/68514. Epub 2018 Jun 30.

26. Kosydar-Bochenek J, Ozga D, Mędrzycka-Dąbrowska W, Lewandowski B. Can resuscitation bring positive changes for paramedics?
Polish experiences. Resuscitation. 2017; 117: e17. doi: 10.1016/j. resuscitation.2017.05.026.

27. Wojciszke B. The negative social world: The Polish culture of complaining. Int J Sociol. 2005; 34: 38-59.

28. Boisclair Demarble J, Fortin C, D'Antonom B, Guay S. Gender Differences in the Prediction of Acute Stress Disorder From Peritraumatic Dissociation and Distress Among Victims of Violent Crimes. J Interpersonal Violence. 2017; 1: 886260517693000. [Epub ahead of print]. doi: 10.1177/0886260517693000.

29. Bunnell BE, Davidson TM, Ruggiero KJ. The Peritraumatic Distress Inventory: Factor structure and predictive validity in traumatically injured patients admitted through a Level I trauma center. J Anxiety Dis. 2018; Apr; 55: 8-13. doi: 10.1016/j.janxdis.2018.03.002. Epub 2018 Mar

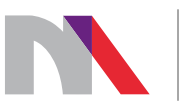

Ministry of Science and Higher Education

Republic of Poland

Generation of the DOI (Digital Object Identifier) - task financed under the agreement No. 618/P-DUN/2019 by the Minister of Science and Higher Education 